\title{
The ability of orthodontists and maxillofacial surgeons in predicting spontaneous eruption of mandibular third molar using panoramic serial radiographs
}

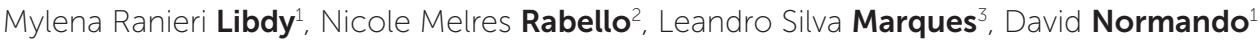

DOI: https://doi.org/10.1590/2177-6709.25.4.068-074.oar

Objective: To evaluate the skill of orthodontists and oral/maxillofacial surgeons (OMFS) in providing a prognosis of mandibular third molars spontaneously erupted, through follow-up panoramic analysis. Methods: 22 orthodontic patients treated without extraction, presenting spontaneously erupted mandibular third molars $(n=44)$ were analyzed through panoramic serial radiographs. The first panoramic radiograph was obtained just after orthodontic treatment (PR1), in patients aging from 13 to 19 years. A second panoramic radiograph (PR2), was obtained in average two years later. The radiographs were randomly analyzed by 54 specialists, 27 orthodontists and 27 OMFS, to obtain the opinion about the approach to be adopted to these teeth in PR1. Then, another opinion was collected by adding a serial radiograph (PR1+2). Results: The concordance of the answers was moderate for OMFS (Kappa $0.44 ; p<0.0001$ ) and significant for orthodontists (Kappa $0.39 ; p<0.0001$ ). In the analysis of the first radiograph (PR1) of the spontaneously erupted molars, OMFS indicated extraction in $44.5 \%$ of cases, while orthodontists indicated in $42 \%$, with no difference between groups $(p=0.22)$. In PR1+2 analysis, orthodontists maintained the same level of extraction indication $(45.6 \%, p=0.08)$, while surgeons indicated more extractions $(63.2 \%, p<0.0001)$. Conclusions: Orthodontists and OMFS were not able to predict the eruption of the third molars that have erupted spontaneously. Both indicated extractions around half of the third molars. A follow-up analysis, including one more radiograph, did not improve the accuracy of prognosis among orthodontists and worsened for OMFS.

Keywords: Third molar. Tooth extraction. Orthodontist. Oral and maxillofacial surgeon.

Objetivo: Avaliar a habilidade de ortodontistas e cirurgiões bucomaxilofaciais (CBMF) em propor um prognóstico para terceiros molares inferiores. Métodos: Foram analisados 22 pacientes tratados ortodonticamente sem extração, cujos terceiros molares inferiores irrompidos espontaneamente $(n=44)$ foram avaliados por meio de radiografias panorâmicas seriadas. A primeira radiografia foi obtida logo após o tratamento ortodôntico (RX1), entre 13 e 19 anos de idade. A segunda radiografia (RX2) foi avaliada dois anos depois, em média. As radiografias foram analisadas aleatoriamente por 54 especialistas, 27 ortodontistas e 27 CBMFs, para obter sua opinião sobre a abordagem a ser adotada na RX1. Em seguida, outra opinião foi coletada adicionando-se a segunda radiografia seriada (RX1+2). Resultados: A concordância das respostas foi moderada para os CBMFs (Kappa $=0,44 ; p<0,0001$ ) e significativa para os ortodontistas (Kappa $=0,39 ; p<0,0001$ ). Após analisar apenas a primeira radiografia (RX1) dos molares antes deles irromperem espontaneamente, os CBMFs indicaram extração em 44,5\% dos casos; enquanto os ortodontistas, em 42\%, sem diferença entre os grupos $(p=0,22)$. Na análise de $\mathrm{RX} 1+2$, os ortodontistas mantiveram o mesmo nível de indicação de extração $(45,6 \%, p=0,08)$, enquanto os cirurgiões passaram a indicar mais extrações $(63,2 \%, p<0,0001)$. Conclusões: Ortodontistas e CBMFs não foram capazes de predizer a erupção de terceiros molares por meio da análise de uma única radiografia panorâmica, indicando extrações em cerca da metade dos terceiros molares examinados. Uma análise de acompanhamento, incluindo mais uma radiografia, não melhorou a precisão do prognóstico entre os ortodontistas, e piorou entre os CBMFs.

Palavras-chave: Terceiro molar. Extração de dente. Ortodontista. Cirurgião bucomaxilofacial.

\footnotetext{
${ }^{1}$ Universidade Federal do Pará, Departamento de Ortodontia (Belém/PA, Brazil).

${ }^{2}$ Associação Brasileira de Odontologia, Departamento de Ortodontia (Belém/PA, Brazil).

${ }^{3}$ Universidade Federal dos Vales do Jequitinhonha e Mucuri, Departamento de Ortodontia (Diamantina/MG, Brazil).
}

» Patients displayed in this article previously approved the use of their facial and intraoral photographs. The authors report no commercial, proprietary or financial interest in the products or companies described in this article.
How to cite: Libdy MR, Rabello NM, Marques LS, Normando D. The ability of orthodontists and maxillofacial surgeons in predicting spontaneous eruption of mandibular third molar using panoramic serial radiographs. Dental Press J Orthod. 2020 July-Aug;25(4):68-74.

DOI: https://doi.org/10.1590/2177-6709.25.4.068-074.oar

Submitted: September 04, 2018 - Revised and accepted: March 25, 2019

Contact address: David Normando - E-mail:davidnormando@hotmail.com 


\section{INTRODUCTION}

Third molars are the most often impacted teeth, ${ }^{1-4}$ with a prevalence ranging from $9.5 \%$ to $39 \%$ among various populations ${ }^{5}$. Moreover, $75 \%$ of people receiving regular dental treatment have the third molars removed ${ }^{6}$. Lack of retromolar space, ${ }^{7-10}$ deficient mandibular growth ${ }^{9}$, distal eruption of dentition, ${ }^{7}$ condylar vertical growth direction, ${ }^{9}$ increased size of the crown, ${ }^{7}$ and late maturing ${ }^{11}$ have been reported as the most common causes of impaction.

The decision to preserve or remove third molars remains unclear to the clinician, partly because of the imprecision of prediction models on impacted molars reported in the literature. ${ }^{12-17}$ Thus, this decision seems to be centered on the preference of each speciality $^{18}$, rather than a clinical approach based on scientific evidence. With so many controversies, prophylactic removal of third molars has been adopted under the assumption of preventing future damage, ${ }^{19}$ such as pericoronitis, ${ }^{2}$ osteitis, osteomyelitis, ${ }^{20}$ dentigerous cysts, ${ }^{21}$ caries in the distal of the second mo$\operatorname{lar}^{22}$, or root resorption in neighboring teeth. ${ }^{23}$ Furthermore, the tertiary crowding in adults ${ }^{24-26}$ and the risk of relapse after orthodontic treatment ${ }^{26}$ have been associated to the presence of third molars, although most studies have demonstrated that third molars have a negligible influence on the long-term changes occurring in the mandibular arch. ${ }^{27,28}$

On the other hand, some risks and complications $^{29}$ may be associated with surgical removal of third molars, including alveolitis, injury to the inferior alveolar nerve, ${ }^{30}$ infections, ${ }^{31}$ and mandibular fracture. ${ }^{32}$ The most conservative approach is to carefully monitor asymptomatic third molars. ${ }^{33}$ This approach is based mainly in the absence of scientific evidence to justify prophylactic extraction. ${ }^{17}$ Monitoring should be performed every two years up to at least the age of $18 .^{8}$

In order to examine the ability of experts on predicting the possibility of eruption of mandibular third molars (M3M), a study showed that orthodontists and oral/maxillofacial surgeons (OMFS) were unable to predict the prognosis of spontaneously erupted M3M after examining a single panoramic radiograph in $38.8 \%$ and $49.6 \%$ of the cases, respectively. ${ }^{17}$ The serial analysis of panoramic radiographs, ${ }^{8}$ a method widely used for clinical moni- toring of orthodontic patients, might be able to increase the accuracy of this prediction. In this sense, the objective of this study is to evaluate the skills of orthodontists and OMFS in providing a prognosis for spontaneously erupted M3M by longitudinal monitoring through panoramic radiographs.

\section{METHODS}

This study was approved by the Human Research Ethics Committee of the Institute of Health Sciences of the Federal University of Pará (CEPICS/UFPA, protocol \# 498024). Each dentist participating signed an Informed Consent Form. In addition, a Use of Database Agreement was signed by the orthodontist who provided patient clinical records and radiographs.

The sample included 22 patients, whose panoramic radiographs, two for each patient $(n=44)$, were obtained from clinical records belonging to a single orthodontist in private practice. They were selected retrospectively from patients who had completed orthodontic treatment without extractions, and whose third molars had spontaneously erupted and were clinically asymptomatic. All patients had at least two panoramic radiographs: the first taken at the end of the orthodontic treatment (PR1, Fig 1A). A second image (PR2, Fig 1B) was obtained around two years after treatment, with the aim of monitoring the eruption of the mandibular third molars. Patients with agenesis, tooth loss, or extraction for orthodontic needs were previously excluded.

Twelve men and 10 women, with a mean age of 14.5 years in the PR1 (13-16.6 years), and 16.8 years in the PR2 (15.5-19.6 years) were evaluated. A male patient, 15.4 years old in PR1 and 16.9 years in the PR2 (Figs 2A and 2B), whose third molars were severely impacted at 21.2 years (Fig $2 \mathrm{C}$ ), was selected as a negative control. The inclusion of this case was carried out by a pilot study, in which five orthodontists unanimously indicated the impaction of the teeth on radiographs when the patient was 21.2 years.

Images of each radiograph was obtained using a digital camera (Canon EOS Digital Rebel EF-S 18-55; Canon Inc., Tokyo, Japan). The images were cropped in order to highlight the region of the mandibular third molars, ramus and angle of the mandible (Figs 1A and 1B). Radiographs were assembled 

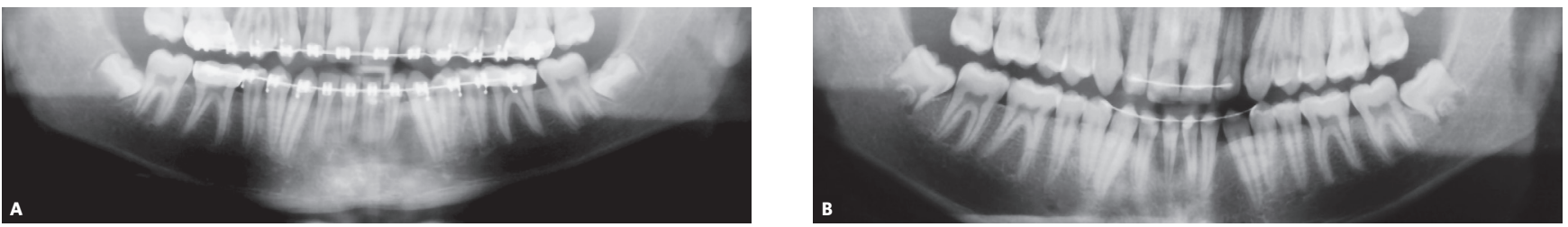

Figure 1 - Panoramic radiograph after orthodontic treatment of the patient \#6 at: A) 14 years and 9 months of age (PR1) and B) 16 years and 7 months (PR2): When examining the PR1, $64.7 \%$ of orthodontists and $29.4 \%$ of OMFS indicated the extraction of left M3M, while $64.7 \%$ of orthodontists and $35.3 \%$ of OMFS indicated the extraction of right M3M. By examining the two radiographs (PR1+2), $23.5 \%$ of orthodontists and $76.4 \%$ of OMFS indicated the extraction of the left M3M, while $17.6 \%$ of orthodontists and $70.6 \%$ of OMFS indicated extraction of the right M3M.
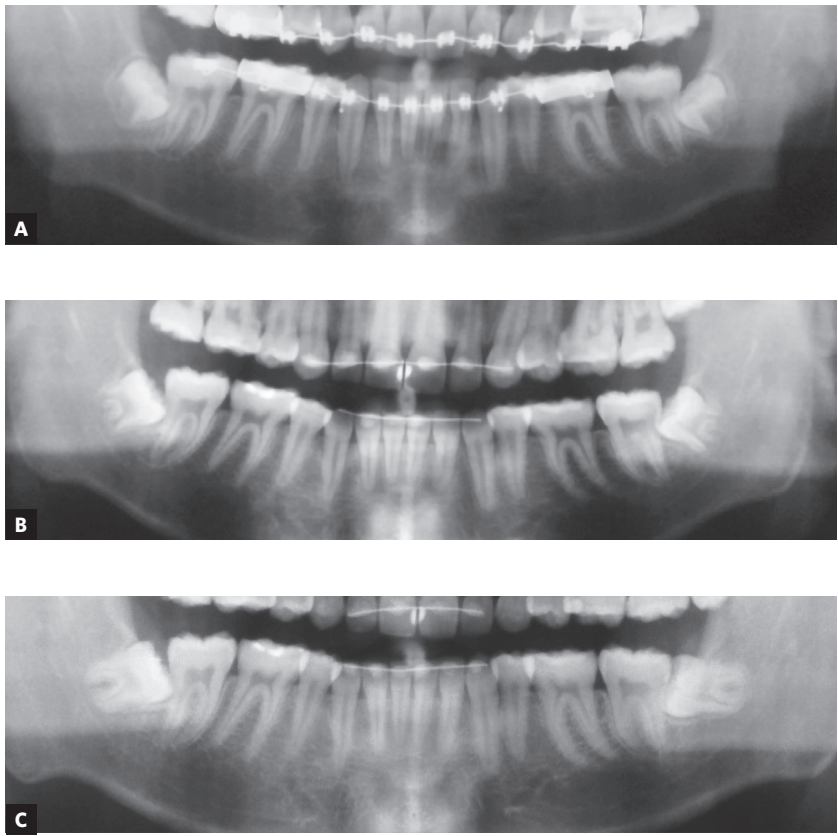

Figure 2 - Panoramic radiograph at: $\mathbf{A})$ the end of orthodontic treatment (PR1) and B) follow-up (PR2), of the patient used as a negative control case. Confirmation of the impaction was defined by a third radiograph $(\mathbf{C})$, at 21.3 years.

randomly in a PowerPoint presentation (Microsoft, Redmond, USA). In addition, the age and sex of each patient were provided.

Fifty-four experts, 27 orthodontists and 27 OMFS, enrolled in the Regional Council of Dentistry of Pará (Brazil) were invited to provide a prognosis for the 44 mandibular third molars. The number of professionals enrolled in this study was based on a previous study ${ }^{18}$, which was shown to have enough power to detect intergroup differences. Three dentists declined to participate in the study (two orthodontists and one OMFS).

The experts first evaluated the panoramic radiographs at the end of orthodontic treatment (PR1) and were requested to indicate a prognosis for M3M bilaterally. The options included: monitoring, extraction, or other. Then, the experts examined the two radiographs together $(\mathrm{PR} 1+2)$ at random, and indicated the prognosis again.

In cases where professionals adopted "extraction" as the preferred treatment for the tooth, they were asked to justify their decision with one of the following six options: 1) the presence or potential to develop a pathology; 2) second molar resorption risk; 3 ) it may lead to crowding; 4) caries risk; 5) tooth impacted or at risk of impaction; 6) other.

These analyses were performed for all 44 M3M that had spontaneously erupted and the negative control, totaling $46 \mathrm{M} 3 \mathrm{M}$ in 23 patients examined through 46 radiographs. Respondents were given sufficient time to respond to the questionnaire.

To evaluate the method error, images of two patients (\#13 and \#15), including four M3M, were duplicated and were reassessed by each of the 54 examiners. The Kappa test was used to examine agreement of the intraexaminer and interexaminers responses. The intragroup and intergroups differences were evaluated by the chi-square test. Data were subjected to statistical analysis, with a significance level of 5\%, using BioEstat 5.3 software (Mamirauá Institute, Belém/Pará, Brazil).

\section{RESULTS}

The analysis of the cases duplicated, corresponding to four $\mathrm{M} 3 \mathrm{M}$, revealed a moderate agreement ${ }^{34}$ among the orthodontists (Kappa $=0.46)$ and OMFS $($ Kappa $=0.47)$ when the PR1 (Table 1) was evaluated. In the following analysis, in which a second radiograph was evaluated together with the first $(\mathrm{PR} 1+2)$, the agreement increased significantly between orthodontists $(\mathrm{Kappa}=0.65)$ and OMFS $(\mathrm{Kappa}=0.67)$. 
Table 1 - Concordance of the answers related to the conduct adopted by oral/maxillofacial surgeons (OMFS) and orthodontists (ORTHO) compared to the third molars in the replicated cases $(n=4)$ when examined the first panoramic radiograph (PR1) or two serial radiographs (PR1+2).

\begin{tabular}{|c|c|c|c|c|c|c|c|c|}
\hline & \multicolumn{4}{|c|}{ PR1 } & \multicolumn{4}{|c|}{ PR1+2 } \\
\hline & \multicolumn{2}{|c|}{ ORTHO } & \multicolumn{2}{|c|}{ OMFS } & \multicolumn{2}{|c|}{ ORTHO } & \multicolumn{2}{|c|}{ OMFS } \\
\hline & RCC & Extraction & $\mathrm{RCC}$ & Extraction & RCC & Extraction & $\mathrm{RCC}$ & Extraction \\
\hline $\mathrm{RCC}$ & 72 & 10 & 53 & 11 & 62 & 11 & 37 & 9 \\
\hline Extraction & 11 & 15 & 16 & 28 & 6 & 29 & 8 & 54 \\
\hline Kappa & \multicolumn{2}{|c|}{0.46} & \multicolumn{2}{|c|}{0.47} & \multicolumn{2}{|c|}{0.65} & \multicolumn{2}{|c|}{0.67} \\
\hline$p$-value & \multicolumn{2}{|c|}{$<0.0001$} & \multicolumn{2}{|c|}{$<0.0001$} & \multicolumn{2}{|c|}{$<0.0001$} & \multicolumn{2}{|c|}{$<0.0001$} \\
\hline
\end{tabular}

$\mathrm{RCC}$ : radiographic clinical control.

Table 2 - Frequency agreement (Kappa), and difference $\left(\mathrm{x}^{2}\right)$ of the responses indicated by orthodontists (ORTHO) and oral/maxillofacial surgeons (OMFS) on the clinical conduct adopted for the M3M that have spontaneously erupted ( $n=44)$, when examined one (PR1) or two serial panoramic radiographs (PR1+2).

\begin{tabular}{|c|c|c|c|c|c|c|c|c|}
\hline \multirow{3}{*}{ Prognosis } & \multicolumn{2}{|c|}{ PR1 } & \multicolumn{2}{|c|}{ PR1+2 } & \multicolumn{4}{|c|}{ PR1 vs PR1+2 } \\
\hline & ORTHO & OMFS & ORTHO & OMFS & \multicolumn{2}{|c|}{ Concordance (Kappa) } & \multicolumn{2}{|c|}{ PR1 vs PR1+2 ( $\left.x^{2}\right)$} \\
\hline & $(n=27)$ & $(n=27)$ & $(n=27)$ & $(n=27)$ & ORTHO & OMFS & ORTHO & OMFS \\
\hline $\mathrm{RCC}$ & $689(58.0 \%)$ & $657(55.3 \%)$ & $646(54.4 \%)$ & $436(36.7 \%)$ & \multirow{6}{*}{$\begin{array}{c}0.44 \\
p<0.0001\end{array}$} & & \multirow{6}{*}{$p=0.08$} & \multirow{6}{*}{$p<0.001$} \\
\hline Extraction & $499(42.0 \%)$ & $529(44.5 \%)$ & $542(45.6 \%)$ & $751(63.2 \%)$ & & 0.39 & & \\
\hline Others & 0 & $2(0.2 \%)$ & 0 & $1(0.1 \%)$ & & $p<0.0001$ & & \\
\hline Total & 1188 & 1188 & 1188 & 1188 & & & & \\
\hline$x^{2}$ ORTHO vs OMFS & \multirow{2}{*}{\multicolumn{2}{|c|}{$\begin{array}{c}1.63 \\
(p=0.22)\end{array}$}} & \multirow{2}{*}{\multicolumn{2}{|c|}{$\begin{array}{c}74.54 \\
(p<0.0001)\end{array}$}} & & & & \\
\hline (p-value) & & & & & & & & \\
\hline
\end{tabular}

RCC: radiographic clinical control.

Table 3 - Frequency agreement (Kappa), difference $\left(x^{2}\right)$ of the responses indicated by orthodontists (ORTHO) and oral/maxillofacial surgeons (OMFS) on the clinica conduct adopted for the impacted M3M $(n=2)$ in the analysis of one (PR1) or two serial panoramic radiographs (PR1+2)

\begin{tabular}{|c|c|c|c|c|c|c|c|c|}
\hline \multirow{3}{*}{ Prognosis } & \multicolumn{2}{|c|}{$\operatorname{PR} 1(n=2)$} & \multicolumn{2}{|c|}{$\operatorname{PR} 1+2(n=2)$} & \multicolumn{4}{|c|}{ PR1 vs PR1+2 } \\
\hline & ORTHO & OMFS & ORTHO & OMFS & \multicolumn{2}{|c|}{ Concordance (Kappa) } & \multicolumn{2}{|c|}{ PR1 vs PR1+2 $\left(x^{2}\right)$} \\
\hline & $(n=27)$ & $(n=27)$ & $(n=27)$ & $(n=27)$ & ORTHO & OMFS & ORTHO & OMFS \\
\hline $\mathrm{RCC}$ & $11(20.4 \%)$ & $14(25.9 \%)$ & $9(16.7 \%)$ & $6(11.1 \%)$ & \multirow{5}{*}{$\begin{array}{c}0.38 \\
p=0.002\end{array}$} & & \multirow{5}{*}{$p=0.8$} & \multirow{5}{*}{$p=0.08$} \\
\hline Extraction & $43(79.6 \%)$ & $40(74.1 \%)$ & $45(83.3 \%)$ & $48(88.9 \%)$ & & 0.52 & & \\
\hline Others & 0 & 0 & 0 & 0 & & $p<0.0001$ & & \\
\hline Total & 54 & 54 & 54 & 54 & & & & \\
\hline $\begin{array}{c}\mathrm{X}^{2} \text { ORTHO } \times \text { OMFS } \\
\text { (p-value })\end{array}$ & \multicolumn{2}{|c|}{$\begin{array}{c}0.24 \\
(p=0.81)\end{array}$} & \multicolumn{2}{|c|}{$\begin{array}{c}3.92 \\
(p=0.08)\end{array}$} & & & & \\
\hline
\end{tabular}

RCC: radiographic clinical control.

Table 4 - Reasons for choosing M3M extractions when orthodontists (ORTHO) and maxillofacial surgeons (OMFS) examined one (PR1) or two serial panoramic radiographs (PR1+2)

\begin{tabular}{|c|c|c|c|c|}
\hline \multirow{3}{*}{ JUSTIFICATIONS } & \multicolumn{2}{|c|}{ PR1 (n=22) } & \multicolumn{2}{|c|}{ PR1+2 (n=22) } \\
\hline & ORTHO & OMFS & ORTHO & OMFS \\
\hline & $(n=27)$ & $(n=27)$ & $(n=27)$ & $(n=27)$ \\
\hline 1. Resorption & $312(45.5 \%)$ & $190(23.0 \%)$ & $187(24.3 \%)$ & $253(20.3 \%)$ \\
\hline 2. Impaction & $255(37.1 \%)$ & $314(38.0 \%)$ & $402(52.3 \%)$ & $431(34.6 \%)$ \\
\hline 3. Tooth decay & $37(5.4 \%)$ & $108(13.0 \%)$ & $79(10.3 \%)$ & $261(20.9 \%)$ \\
\hline 4. Pathology & $53(7.7 \%)$ & $111(13.42 \%)$ & $73(9.5 \%)$ & $208(16.7 \%)$ \\
\hline 5. Crowding & $27(4.0 \%)$ & $56(6.8 \%)$ & $28(3.6 \%)$ & $36(3.0 \%)$ \\
\hline 6. Others & $2(0.3 \%)$ & $48(5.80 \%)$ & 0 & $57(4.5 \%)$ \\
\hline Total & 686 & 827 & 769 & 1246 \\
\hline
\end{tabular}


In the analysis of the first panoramic radiograph (PR1), the OMFS indicated extraction in $44.5 \%$ of cases, while orthodontists indicated extraction in $42 \%$, with no difference between them $(p=0.22$, Table 2). In PR1+2, orthodontists maintained a similar level of extractions, when compared to the PR1 analysis $(45.6 \%, p=0.08)$, while the OMFS indicated more extractions $(63.2 \%, p<0.0001$, Table 2). The Kappa agreement for only one radiograph, compared to using both radiographs (PR1+2), where the M3M erupted spontaneously (Table 2), was moderate for orthodontists $(\mathrm{Kappa}=0.44)$ and considerable for OMFS (Kappa $=0.39)$.

In examining the impacted M3M (Fig 2, Table 3), orthodontists indicated extraction in 79.6\% of the responses when examining a single panoramic radiograph (PR1). For OMFS, extraction was pointed out on $74.1 \%$, with no significant difference between the two groups of examiners $(p=0.81)$. When assessing PR1+2, 83.3\% of orthodontists indicated extraction, while this option was indicated by $88.9 \%$ of the OMFS $(p=0.08)$. Compared to PR1, orthodontists and OMFS indicated, respectively, 3.7\% $(p=0.8)$ and $14.8 \%(p=0.08)$ more extraction when evaluating PR1+2 in cases of impaction. Kappa values for the agreement between PR1 and PR1+2 was 0.52 for OMFS and only 0.38 for orthodontists (Table 3).

In the PR1 analysis, the most prevalent justification for extraction among the orthodontists was "risk of resorption of the second molar" (45.5\%), while for OMFS it was "impacted tooth or at risk of impaction" (38\%). In PR1+2, both orthodontists and OMFS indicated "impaction" as their main justification (52.3\% and $34.6 \%$, respectively).

\section{DISCUSSION}

The pathway of the third molars eruption have been the aim of several studies, ${ }^{5,10,14}$ but it has not yet been possible to develop a reliable predictive model. ${ }^{12-17}$ The prevalence of third molar impaction ranges from $9.5 \%$ to $39 \%$ among various populations. ${ }^{5}$ Third molars become more uprighted until 25 years of age, usually erupting between 18 and 24 years of age $\mathrm{e}^{6}$ This fact is due to changes in the sagittal position, which has been found in posttreatment follow-up of orthodontic patients.
The present findings showed that when mandibular third molars erupt spontaneously, about $42 \%$ of orthodontists and $44.5 \%$ of OMFS indicated the extraction when evaluating a single panoramic radiograph taken at the end of orthodontic treatment (Table 2). However, when two serial radiographs from the same patient are examined, OMFS indicated significantly more extractions $(63.2 \%, p<0.0001)$, while orthodontists tended to maintain the same opinion. These data reveal that the longitudinal follow-up by analysis of serial panoramic radiographs did not improve the accuracy of prognosis among orthodontists, and worsened the prognosis for surgeons.

For one patient in which both M3M were clearly impacted in the long-term follow-up (Fig 2, Table 3), it was found that the majority of professionals $(79.6 \%$ of orthodontists and 74.1\% of OMFS) indicated the extraction of third molars after examining the first radiograph (PR1). By adding a second serial radiograph (PR1+2), orthodontists indicated the same amount of extractions $(83.3 \%$, $p=0.8$ ), while OMFS indicated extraction in nearly $89 \%$ of cases, an increase of $14.8 \%$ compared to PR1, although not significantly different $(p=0.08)$. A larger sample size of impacted teeth could detect this tendency of change in the prognosis. However, this fact corroborates the results obtained in the analysis of cases in which third molars erupted spontaneously, where OMFS tended to indicate more extractions when two serial radiographs were evaluated $(\mathrm{PR} 1+2)$, regardless of the final position of these teeth.

In summary, in cases of mandibular third molar impactions, the prediction ability of OMFS seems to improve slightly when a longitudinal series of two radiographs is presented. However, it is worsened when the third molars erupt spontaneously. Among the orthodontist, no difference was observed, and for cases of spontaneous eruption, a correct prognosis is similar to the probability of choice by chance (50\%). Thus, it seems that OMFS indicate more surgical removal of third molars when analyzing radiographs in which these teeth are in a more advanced stage of development.

Furthermore, since OMFS make decisions for more extractions than orthodontists in PR1+2, a lower intergroup agreement coefficient was found, when compared to the PR1 analysis.

When assessing the radiograph obtained at the end of the orthodontic treatment (PR1), the main reason among orthodontists to indicate extraction was the possibility of resorption of the second molar 
(45.5\%) (Table 4). For OMFS, the main reason was the risk of impaction of third molars (38\%). These findings may be associated with the pathway eruption of third molars with a mesial angulation. ${ }^{35}$ This angulation could lead to a more intimate contact with the adjacent tooth, leading professionals to plan a prophylactic extraction of $\mathrm{M} 3 \mathrm{M}$ in order to prevent future pathological processes. 2,21,23 Thus, despite the similar display of surgical removal between the orthodontists and OMFS, the reasons for the indication appear to be different.

With PR1+2 analysis, the reason reported by most respondents for the indication of extraction of $\mathrm{M} 3 \mathrm{M}$ was the risk of impaction for both orthodontists (52.3\%) and OMFS (34.6\%, Table 4). It is likely that the advanced root development and the end of the retromolar space growth, widely reported factors of third molar impaction, ${ }^{8,36}$ have contributed to the reasons for their choice.

As the average age of the subjects in the present study was 14.5 years in PR1 and 16.8 years in PR2, a more conservative strategy would be to follow third molar development and position, by clinical and radiographic evaluation, until adulthood ${ }^{2}$. Also, active monitoring at 24-month intervals is recommended to allow the disclosure of clinical progression of periodontal disease ${ }^{37}$ and this was the time period evaluated in this study. In contrast, when these teeth are the cause of some painful symptoms, there is a general consensus for extraction. ${ }^{38}$

In asymptomatic cases, regular monitoring is required, making questionable the risks of maintaining the patient, taking into account the patient's general state of health and the potential risk of systemic involvement. ${ }^{39}$ Whenever indicating extraction of third molars, dentists should have a justifiable reason, taking into account future treatment planning from an orthodontic, surgical, periodontal and/or prosthetic point of view. ${ }^{40}$ At the same time, a cost/benefit analysis should be carried out to justify the prophylactic removal of third molars.

The analysis of replicability of the cases studied showed greater concordance of responses when the two serial radiographs were examined $(\mathrm{PR} 1+2)$ for both groups of evaluators (Table 1). This result seems to suggest that the higher the stage of development of the third molar, the greater agreement will be observed. However, this fact does not ensure a more accurate prognosis, whereas among OMFS, the level of error in the prognosis increased when the two radiographs were examined concurrently, at least for spontaneously erupted teeth.
The evaluation of panoramic radiographs to suggest an accurate diagnosis was a limiting factor in this study. Although radiographs are currently used as the main instrument to observe and monitor third molars, this method does not replace clinical evaluation of the patient. Computed tomography (CT) is considered a more accurate technique to evaluate the involvement of anatomical structures, such as the mandibular canal, with the mandibular third molars. However, the ability of professionals to predict the eruption of these teeth using CT demonstrated that a three-dimensional image does not seem to change the prognosis established by specialists. ${ }^{41}$

The most important finding of this study is the information that clinical decision to extract M3M can be precipitated and often misguided when based on twodimensional radiographic examinations. The results showed that even if the radiographs are taken longitudinally, the accuracy of prognosis is not increased. Furthermore, it seems to exist a need for prospective longitudinal studies evaluating the consequence of surgical removal of mandibular third molars, as well as for clinical and radiographic control. ${ }^{38}$

\section{CONCLUSIONS}

These results allow us to conclude that orthodontists and oral/maxillofacial surgeons are not able to predict the prognosis of erupted mandibular third molars by examining a single panoramic radiograph. Both indicate extractions in almost half of spontaneously erupted teeth. Furthermore, the addition of a serial radiograph did not improve the accuracy of prognosis among orthodontists and worsened the accuracy for surgeons. Thus, it is suggested that these experts should re-evaluate their clinical protocol as well as radiographic guides used to establish a reliable prognosis on the eruption of third molars. 


\section{Authors contribution (ORCID ${ }^{(0)}$}

\author{
Mylena R. Libdy (MRL): 0000-0002-4976-5296 \\ Nicole M. Rabello (NMR): 0000-0002-6831-209X \\ Leandro S. Marques (LSM): 0000-0002-7089-8739 \\ David Normando (DN): 0000-0002-1335-1040
}

Conception or design of the study: MRL, DN. Data acquisition, analysis or interpretation: MRL, NMR, LSM, DN. Writing the article: MRL, NMR, LSM, DN. Critical revision of the article: MRL, NMR, LSM, DN. Final approval of the article: MRL, NMR, LSM, DN. Obtained funding: MRL, DN. Overall responsibility: MRL, DN.

\section{REFERENCES}

1. Shiller WR. Positional changes in mesio-angular impacted mandibular third molars during a year. J Am Dent Assoc. 1979 Sept;99(3):460-4

2. Kahl B, Gerlach KL, Hilgers RD. A long-term, follow-up, radiographic evaluation of asymptomatic impacted third molars in orthodontically treated patients. Int J Oral Maxillofac Surg. 1994 Oct:23(5):279-85

3. Richardson ME. The etiology and prediction of mandibular third molar impaction. Angle Orthod. 1977 July:47(3):165-72

4. Hattab FN. Positional changes and eruption of impacted mandibular third molars in young adults. A radiographic 4-year follow-up study. Oral Surg Oral Med Oral Pathol Oral Radiol Endod. 1997 Dec;84(6):604-8.

5. Richardson M. Changes in lower third molar position in the young adult. Am J Orthod Dentofacial Orthop. 1992 Oct;102(4):320-7.

6. Schulhof RJ. Third molars and orthodontic diagnosis. J Clin Orthod. 1976 Apr:10(4):272-81

7. Bjork A, Jensen E, Palling M. Mandibular growth and third molar impaction. Acta Odontol Scand. 1956; 14:231-72.

8. Olive R, Basford K. Reliability and validity of lower third molar space-assessment techniques. Am J Orthod. 1981 Jan;79(1):45-53.

9. Behbehani F, Artun J, Thalib L. Prediction of mandibular third-molar impaction in adolescent orthodontic patients. Am J Orthod Dentofacial Orthop. 2006 July:130(1):47-55

10. Uthman AT. Retromolar space analysis in relation to selected linear and angular measurements for an Iraqi sample. Oral Surg Oral Med Oral Pathol Oral RadiolEndod. 2007 Aug:104(4):76-82

11. Bishara SE, Andreasen G. Third molar: A review. Am J Orthod. 1983 Feb;83(2):131-7.

12. De-La-Rosa G, Valmaseda C, Gay-Escoda C. Spontaneous third-molar eruption after second-molar extraction in orthodontic patients. Am J Orthod Dentofacial Orthop. 2006 Mar:129(3):337-44

13. Begtrup A, Gronasto H, Christensen IJ, Kjaer I. Predicting lower third molar eruption on panoramic radiographs after cephalometric comparison of profile and panoramic radiographs. Eur J Orthod. 2013 Aug:35(4):460-6.

14. Ghougassian SS, Ghafari JG. Association between mandibular third molar formation and retromolar space. Angle Orthod. 2014 Nov;84(6):946-50.

15. Toro F, Aravena H, Mayoral G. Evolución seguida por los terceros molares inferiores durante el tratamiento de Ortodoncia. Rev Iberoam Ortod. 1984;4(1):55-68.

16. Staggers JA, Germane N, Fortson WM. A comparison of the effects of first premolar extractions on third molar angulation. Angle Orthod. 1991 Aug:62(2):135-138.

17. Costa MG, Pazzini CA, Pantuzo MCG, Jorge MLR, Marques LS. Is there justification for prophylactis extraction of third molars? A systematic review. Braz Oral Res. 2013 Mar-Apr;27(2):183-8.

18. Bastos AC, Oliveira JB, Mello KFR, Leão PB, Artese F, Normando D. The ability of orthodontists and oral/maxillofacial surgeons to predict eruption of lower third molar. ProgOrthod. 2016 Dec;17(1):21.

19. Friedman JW. The prophylactic extraction of third molars: a public health hazard. Am J Public Health. 2007 Sept; 97(9):1554-9.

20. Miyamoto I, Ishikawa A, Morimoto Y, Takahashi T. Potential risk of asymptomatic osteomyelitis around mandibular third molar tooth for aged people: a computed tomography and histopathologic study. PLoS One. 2013 Sept:8(9):73897.
21. Wali GG, Sridhar V. Shyla HN. A study on dentigerous cystic changes with radiographically normal impacted mandibular third molars. J Maxillofac Oral Surg. 2012 Dec;11(4):458-65

22. Falci SG, Castro CR, Santos RC, Souza Lima LD, Ramos-Jorge ML, Botelho AM, et al. Association between the presence of a partially erupted mandibular third molar and the existence of caries in the distal of the second molars. Int J Oral Maxillofac Surg. 2012 Oct; 41(10):1270-4.

23. Peterson LJ. Rationale for removing impacted teeth: when to extract or not to extract. J Am Dent Assoc. 1992 July:123(7):198-204.

24. Elsey MJ, Rock WP. Influence of orthodontic treatment on development of third molars. Br J Oral Maxillofac Surg. 2000 Aug; 38(4):350-53.

25. Knutsson K, Lysell L, Rohlin M. Dentists' decisions on prophylactic removal of mandibular third molars: a 10-year follow-up study. Community Dent Oral Epidemiol. 2001 Aug:29(4):308-14.

26. Rocha Junior JF, Peroni LD, Ribeiro LL, Silveira PAS, Santoro LC. Removal of third molars: orthodontic reasons. J Bras Ortodon Ortop Facial. 2002 JanFeb;7(37):51-62

27. Adaki SR, Yashodadevi BK, Sujatha S, Santana N, Rakesh N, Adaki R. Incidence of cystic changes in impacted lower third molar. Indian J Dent Res. 2013 MarApr; 24(2):183-7.

28. Zhang $Q B$, Zhang ZQ. Early extraction: a silver bullet to avoid nerve injury in lower third molar removal? Int J Oral Maxillofac Surg. 2012 Oct;41(10):1280-3.

29. Cunha-Cruz J, Rothen M, Spiekerman C, Drangsholt M, McClellan L, Huang GJ. Recommendations for third molar removal: a practice-based cohort study. Am J Public Health. 2014 Apr;104(4):735-43.

30. Bataineh AB. Sensory nerve impairment following mandibular third molar surgery. J Oral Maxillofac Surg. 2001 Sept;59(9):1012-7.

31. Chiapasco M, De Cicco L, Marrone G: Side effects and complications associated with third molar surgery. Oral Surg Oral Med Oral Pathol. 1993 Oct; 76(4):412-20

32. Krimmel M, Reinert S. Mandibular fracture after third molar removal. J Oral Maxillofac Surg. 2000 Oct:58(10):1110-2.

33. Mettes TD, Ghaeminia H, Nienhuijs ME, Perry J, van der Sanden WJ, Plasschaert A. Surgical removal versus retention for the management of asymptomatic impacted wisdom teeth. Cochrane Database Syst Rev. 2012 Jun; (6):CD003879.

34. Viera AJ, Garrett JM. Understanding interobserver agreement: the kappa statistic. Fam Med. 2005 May:37(5):360-3.

35. Sewerin I, Wowern N. A radiographic four-year follow-up study of asymptomatic mandibular third molars in young adults. Int Dent J. 1990 Feb;40(1):24-30

36. Ledyard JR BC. A study of the mandibular third molar area. Am J Orthod. 1953 May;39(5):366-73

37. Dodson TB, Cheifetz ID, Nelson WJ, Rafetto LK. Summary of the proceeding of the Third Molar Multidisciplinary Conference. J Oral Maxillofac Surg. 2012 Sept:70(9 Suppl 1):S66-9.

38. Guralnick G, Laskin D. NIH consensus development conference for removal of third molars. J Oral Surg. 1980 Mar;38(3):235-6.

39. Vig KW. Patient specific variables are a consideration in the decision to extract asymptomatic third molars. J Evid Based Dent Pract. 2012 Jun;12(2):92-4

40. Normando, D. Third molars: To extract or not to extract? Dental Press J Orthod. 2015 Jul-Aug:20(4):17-8

41. Moreira PEO, Normando D, Pinheiro LR, Bradão GAM. Prognosis of the impacted lower third molars: panoramic reconstruction versus tomographic images. Oral Surg Oral Med Oral Pathol Oral Radiol. 2020. in press. https://doi.org/10.1016/j.0000.2020.07.006 